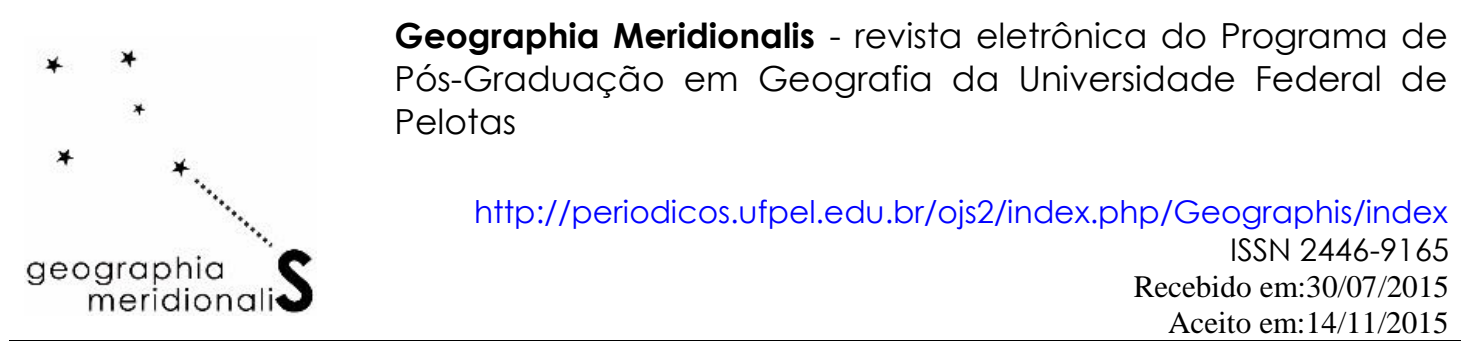

\title{
PROPOSTA DE UMA (GEO)IDENTIDADE VISUAL PARA CAÇAPAVA DO SUL, "CAPITAL GAÚCHA DA GEODIVERSIDADE"
}

\author{
André Weissheimer de Borba \\ Universidade Federal de Santa Maria, \\ Av. Roraima, 1000, prédio 17, Camobi 97.105-900, \\ Santa Maria/RS, Brasil, \\ awborba.geo@gmail.com
}

O município de Caçapava do Sul, localizado na região centro-sul do Estado do Rio Grande do Sul, destaca-se por sua geodiversidade. Em seus $3.047 \mathrm{~km}^{2}$ de área, possui uma diversidade de contextos geológicos sem paralelo em escala estadual. Possui ocorrências de todos os principais tipos de rochas (plutônicas, vulcânicas, sedimentares e metamórficas), estruturas tectônicas (falhas, dobras), mineralizações e feições resultantes de diversos processos terrestres. Seu território pode ser dividido em quatro grandes contextos geológicos (Borba et al., 2013): (a) um embasamento antigo, com rochas metamórficas de origens e composições diversas, como gnaisses, xistos básicos e ultrabásicos, metarenitos, metapelitos e mármores; (b) sucessões vulcânicas e sedimentares, de origem marinha e continental, com idades entre 630 e 550 Ma, reunidas nas unidades Maricá e Bom Jardim; (c) uma intrusão granítica (sienoa monzogranitos) em forma de elipse, na porção central do município, que conforma o alto topográfico onde se localiza a sede urbana; e (d) sucessões sedimentares continentais, avermelhadas, de origem flúvio-lacustre e eólica, reunidas nas unidades Santa Bárbara e Guaritas (Figura 1).

Tais atributos geológicos constituem o registro de uma evolução longa e complexa, que se iniciou há mais de 2 bilhões de anos: no território do município há evidências de fundos oceânicos e mares tropicais muito antigos, erupções vulcânicas de diferentes composições e estilos, granitos cristalizados nas profundezas da Terra, e rios cascalhosos de grande energia que corriam em um grande deserto dos primórdios do supercontinente Gondwana. A evolução mais recente, vinculada aos processos geomorfológicos, é igualmente interessante. As formas de relevo e as paisagens de Caçapava do Sul, além de possuírem a rara beleza das Guaritas e da Serra do Segredo, são evidências claras das variações climáticas dos últimos milhares de anos: climas úmidos e climas secos sucederam-se, acompanhando os períodos 
glaciais e interglaciais do continente sul-americano. Fósseis de grandes mamíferos desse passado mais recente, como preguiças-gigantes, foram identificados em Caçapava do Sul e ajudam a contar a fantástica história geológica registrada no município.

Figura 1 - Mapa geológico esquemático do município de Caçapava do Sul (esquerda), com seus quatro principais contextos geológicos, e sua localização no Estado do Rio Grande do Sul.

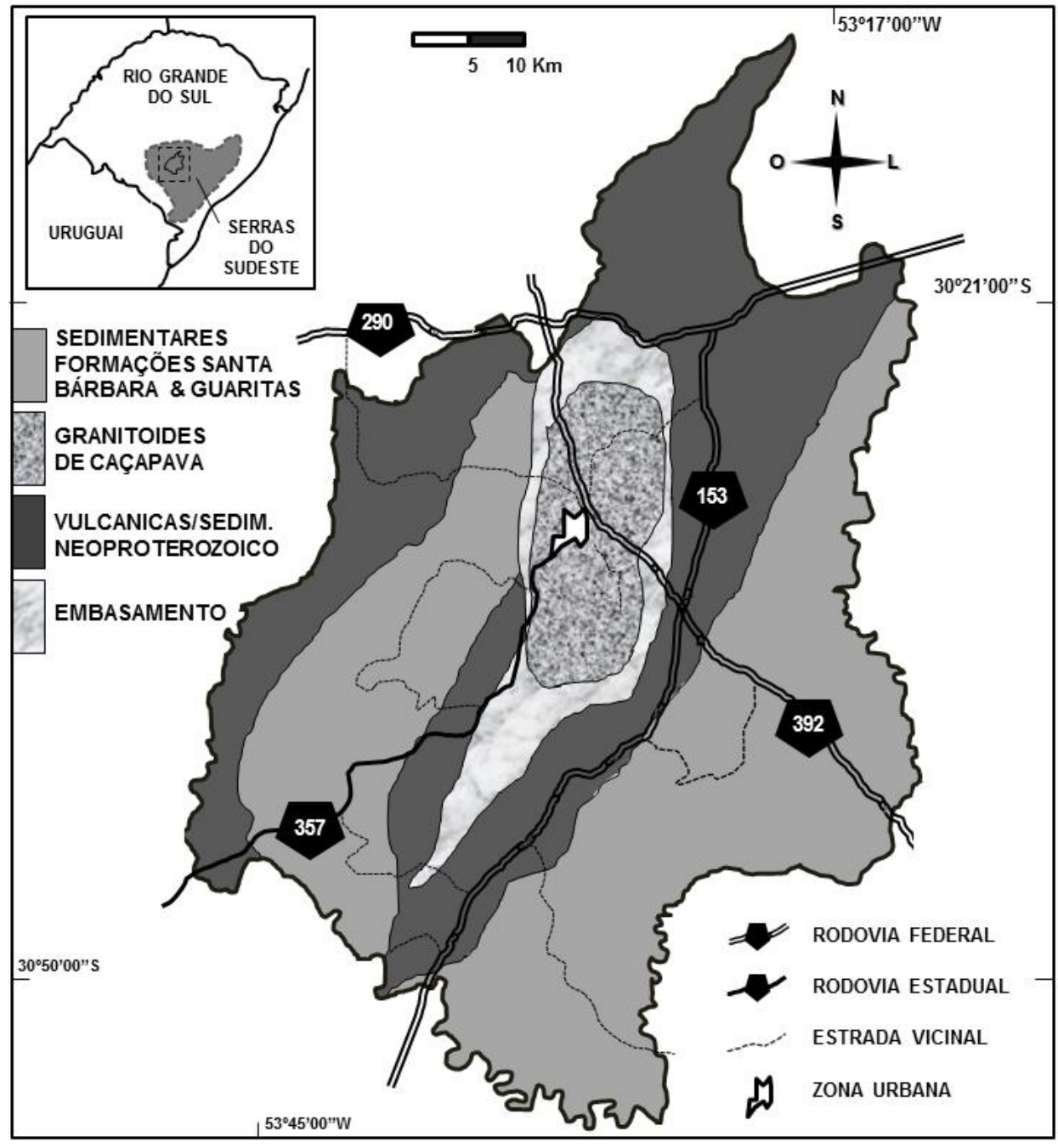

Fonte: (modificado de Borba et al., 2013).

A excelência didática das exposições de rocha e das paisagens de Caçapava do Sul tem trazido àquele município, nos últimos 50 anos, grupos numerosos de profissionais, pesquisadores, professores e estudantes de todas as ciências da Terra e da vida, não apenas das escolas gaúchas de geologia, geografia e biologia, mas também de outras regiões do Brasil, para adquirirem ou aperfeiçoarem seus conhecimentos. Neste sentido, pode-se afirmar que o município é uma incomparável "sala de aula ao ar livre" para o ensino das geociências em todas as suas vertentes. A afinidade de Caçapava do Sul com o ensino e a pesquisa em geociências já resultou na implantação de um núcleo avançado da Universidade do Vale do Rio dos Sinos (Unisinos) e, atualmente, se reflete na consolidação do campus da

\begin{tabular}{llllll}
\hline Geographia Meridionalis & v. 01, n. 02 & Jul-Dez/2015 & p. 405-411 & Página & 406
\end{tabular}


Universidade Federal do Pampa (Unipampa), que oferece os cursos de Geologia, Geofísica e Tecnologia em Mineração, todos em nível de graduação e todos relacionados à geodiversidade do município.

Em termos econômicos, a geodiversidade de Caçapava do Sul oferece recursos minerais decisivos para a economia do Estado. As ocorrências de minérios metálicos (cobre, ouro, prata, chumbo, zinco, entre outros) foram intensamente exploradas no passado, e seu aproveitamento experimenta hoje uma possível retomada. Os mármores da região das Caieiras, muito próximos da zona urbana, a partir dos quais se obtém o calcário, são imprescindíveis à agricultura de grãos do norte do Estado, no sentido de corrigir o pH ácido dos solos gaúchos. Nos solos rasos e pedregosos de Caçapava do Sul, começam a vicejar vinhedos e olivais. Também no campo da economia, destaca-se aqui o potencial turístico do município, cuja geodiversidade se reflete igualmente na variedade de atividades possíveis para turistas (turismo rural, ecoturismo, observação de aves, turismo histórico-cultural, turismo geológico) e praticantes de esportes de aventura na natureza (trilhas pedestres, mountain bike, escalada, voo livre, caiaque, etc.).

Para que todo esse potencial seja transformado em desenvolvimento humano e socioeconômico sustentável, uma abrangente estratégia de geoconservação tem sido planejada no âmbito das universidades da região (UFSM, UFPel e Unipampa), com articulação política junto a autoridades municipais e estaduais. Recentemente, ocorreu uma conquista importante: o município de Caçapava do Sul foi reconhecido oficialmente, pela Assembleia Legislativa do RS, como a "capital gaúcha da geodiversidade", através de Lei Ordinária Estadual 14.708, sancionada pelo governador do Estado em 15 de julho de 2015 (Rio Grande do Sul, 2015). Imagina-se que esse reconhecimento possa representar o início de um saudável ciclo de curiosidade e valorização do município, tanto em nível estadual quanto internamente, junto à comunidade local. Esse título poderá ser utilizado na promoção: (a) dos atrativos geoturísticos e de aventura na natureza; (b) dos produtos locais de gastronomia e artesanato vinculados à geodiversidade, como mel, vinhos e azeites; (c) dos produtos minerais, como calcário, cal e argamassa; (d) dos cursos relacionados às geociências oferecidos pela Unipampa; (d) de hotéis, pousadas e fazendas de turismo rural; entre outros.

A curiosidade e o interesse por esse reconhecimento também já estão na pauta dos professores de ciências naturais da rede pública, tanto municipal quanto estadual, que estão recebendo aperfeiçoamento em temas relacionados à geodiversidade local, no âmbito de projetos de extensão da UFSM (Borba et al., 2015). O desafio, nesse caso, é o de reverter um 
quadro de baixa escolaridade entre os adultos, de evasão escolar e atrasos na seriação entre as crianças, bem como de fraco desempenho em exames nacionais na área de ciências da natureza.

Esse conjunto de iniciativas, inspiradas pela geodiversidade local, necessita de uma identidade visual, que possa ser utilizada em projetos, em selos de qualidade, em apresentações e em peças promocionais de mídia, etc. Com esse objetivo em mente, apresenta-se aqui uma proposta de "(geo)identidade visual” para o município, uma nova logomarca para as atividades que focalizem a geodiversidade local. A logomarca proposta, construída no âmbito de projetos de pesquisa e extensão coordenados pelo autor, já tem sido utilizada pontualmente durante oficinas e minicursos para os professores locais, bem como em apresentações sobre o potencial turístico do município. A "(geo)identidade visual" proposta (Figura 2) constitui uma versão simplificada, geométrica e estilizada, produzida no software Microsoft ${ }^{\circledR}$ PowerPoint ${ }^{\circledR}$, do mapa de contextos geológicos apresentado na Figura 1. Todos os elementos na logomarca possuem significado geológico e estratigráfico próprio, conforme segue abaixo:

(a) o embasamento metamórfico está representado em cor verde-oliva clara (R:195, G:214, B:155), para lembrar que as condições dominantes de metamorfismo na área são de fácies xistos-verdes; a figura geométrica que representa esse contexto, alongada na direção vertical (altura $7,72 \mathrm{~cm}$, largura $3,19 \mathrm{~cm}$ ), possui dois cantos diagonais opostos em ângulo reto (superior direita e inferior esquerda) e os dois outros cantos arredondados, conformando curvas (superior esquerda e inferior direita), representando assim o cisalhamento característico dos processos de deformação pelos quais passaram essas rochas metamórficas;

(b) as sucessões sedimentares e vulcânicas mais antigas estão representadas em marrom claro (R:148, G:138, B:84), cor predominante entre as rochas das unidades Maricá e Bom Jardim; a figura geométrica é um retângulo pouco alongado na direção vertical (altura $8,74 \mathrm{~cm}$, largura $8,13 \mathrm{~cm}$ ), respeitando assim os limites do contexto geológico e do próprio município;

(c) a intrusão granítica é representada por um retângulo de arestas encurvadas, alongado na vertical (altura 4,95 cm, largura 2,32 cm), para acompanhar a orientação N-S do corpo intrusivo mapeado em Caçapava do Sul; sua cor é um rosa claro (R:217, G:150, B:148), tom geralmente utilizado para a representação de rochas graníticas em mapas geológicos; 
(d) dois triângulos retângulos de dimensões iguais (altura 3,78 cm, largura 6,99 cm), rotacionados $90^{\circ} \mathrm{em}$ sentidos opostos para o interior da figura e posicionados de forma espelhada, situam-se sobre os cantos inferior direito e superior esquerdo do retângulo marrom; preenchidos com a cor laranja clara (R:250, G:192, B:144), eles representam as áreas de afloramento (Figura 1) de rochas sedimentares continentais, mais jovens, reunidas nas formações Santa Bárbara e Guaritas, e que incluem as formas de relevo mais interessantes do município (as Pedras das Guaritas e a Serra do Segredo);

(e) por fim, cabe salientar os diferentes sombreamentos das figuras geométricas, os quais são responsáveis por sugerir a estratigrafia e a relação de idades entre os contextos geológicos representados na logomarca; a figura verde, que representa o embasamento, possui um sombreamento interno em suas porções superior e esquerda, para sugerir uma unidade mais antiga, geologicamente "abaixo" das demais, e formada por processos de profundidade, com altas pressões e temperaturas; o retângulo rosa de bordas encurvadas, que representa os granitos, possui um sombreamento externo em suas porções inferior e esquerda, sugerindo uma posição mais alta em relação à porção verde-oliva, para representar não apenas que os granitos intrudem o embasamento, sendo portanto mais jovens, mas também que formam o alto topográfico principal do município, onde está a cidade; por fim, os triângulos opostos que representam as formações Santa Bárbara e Guaritas possuem sombreamentos externos também opostos, em direção ao interior da figura, para reforçar seu caráter de unidades mais jovens, que "recobrem" (em termos geológicos, mas também geométricos) as demais unidades;

(f) em complemento, também na cor marrom clara (R:148, G:138, B:84), aparecem duas inscrições em fonte "Calibri”: acima do mapa estilizado, aparecem as palavras “caçapava" (fonte 80) e "do sul" (fonte 44), deslocada, alinhando-se à direita com "caçapava"; e, abaixo das figuras geométricas, as palavras "capital gaúcha da" (fonte 42) e, ainda abaixo dessas, centralizada com as anteriores, "geodiversidade" (fonte 52); as palavras "caçapava" e "geodiversidade" possuem um espaçamento entre caracteres condensado em 3pt., enquanto os termos "do sul" e "capital gaúcha da" possuem espaçamento condensado em 1,5pt; nenhuma letra maiúscula foi utilizada na logomarca; o plano de fundo é de cor preta sólida.

A proposta da (geo)identidade visual aqui apresentada, longe de ser um "registro de marca", objetiva divulgar o reconhecimento de Caçapava do Sul como a "capital gaúcha da

\begin{tabular}{llllll}
\hline Geographia Meridionalis & v. 01,n. 02 & Jul-Dez/2015 & p. 405-411 & Página & 409
\end{tabular}


geodiversidade" entre a comunidade acadêmica gaúcha, estimulando assim mais pesquisas e contribuições para iniciativas e estratégias de geoconservação. A percepção dos valores científico, educativo, cultural, ecológico e econômico da geodiversidade de Caçapava do Sul certamente é um passo importante para o desenvolvimento humano e socioeconômico do município e de sua população, de maneira integrada com um meio ambiente equilibrado e conservado.

Figura 2 - Logomarca proposta como "(geo)identidade visual" para o reconhecimento obtido pelo município de Caçapava do Sul como a "capital gaúcha da geodiversidade".

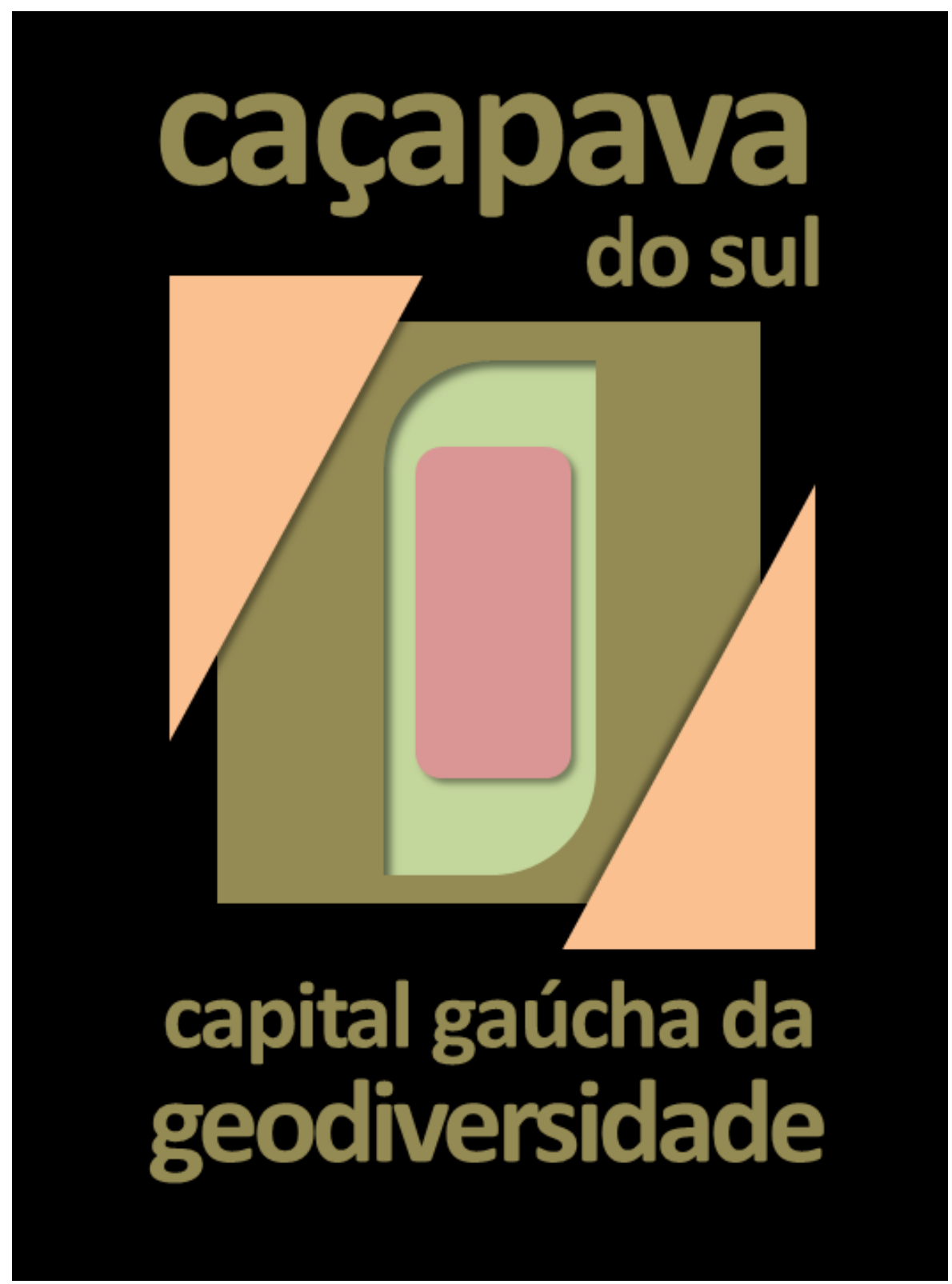




\section{REFERÊNCIAS}

BORBA A.W., SOUZA L.F., MIZUSAKI A.M.P., ALMEIDA D.P.M., STUMPF P.P. 2013. Inventário e avaliação quantitativa de geossítios: exemplo de aplicação ao patrimônio geológico do município de Caçapava do Sul (RS, Brasil). Pesquisas em Geociências, 40(3): 275-294.

BORBA A.W., TEIXEIRA K.M., FERREIRA P.F., FERREIRA P.F. 2015. Concepções de professores de ciências naturais de Caçapava do Sul (RS, Brasil) sobre geologia local: subsídios à educação geopatrimonial. Terra e Didatica, 11(2): 117-124.

RIO GRANDE DO SUL. 2015. Lei 14.708, de 15 de julho de 2015, declara o município de Caçapava do Sul "capital gaúcha da geodiversidade". DOE, Edição de 16/7/2015, disponível em:

http://www.servico.corag.com.br/diarioOficial/verJornal.php?pg=001\&jornal=doe\&dt=1607-2015, consultada em 22/09/2015. 